\title{
Cannabis in the Treatment of Dystonia, Dyskinesias, and Tics
}

\author{
Barbara S. Koppel ${ }^{1}$ (D)
}

Published online: 14 August 2015

(C) The American Society for Experimental NeuroTherapeutics, Inc. 2015

\begin{abstract}
Cannabis has been used for many medicinal purposes, including management of spasms, dystonia, and dyskinesias, with variable success. Its use for tetanus was described in the second century $\mathrm{BCE}$, but the literature continues to include more case reports and surveys of its beneficial effects in managing symptoms of hyperkinetic movement disorders than randomized controlled trials, making evidence-based recommendations difficult. This paper reviews clinical research using various formulations of cannabis (botanical products, oral preparations containing $\Delta^{9}$-tetrahydrocannabinol and/or cannabidiol) and currently available preparations in the USA (nabilone and dronabinol). This has been expanded from a recent systematic review of cannabis use in several neurologic conditions to include case reports and case series and results of anonymous surveys of patients using cannabis outside of medical settings, with the original evidence classifications marked for those papers that followed research protocols. Despite overlap in some patients, dyskinesias will be treated separately from dystonia and chorea; benefit was not established beyond individual patients for these conditions. Tics, usually due to Tourettes, did respond to cannabis preparations. Side effects reported in the trials will be reviewed but those due to recreational use, including the dystonia that can be secondary to synthetic marijuana preparations, are outside the scope of this paper.
\end{abstract}

Barbara S. Koppel

Barbara.Koppel@nychhc.org

1 New York Medical College, Metropolitan Hospital, 1901 First Ave. Suite 7C5, New York, NY 10029, USA
Keywords Cannabis · Marijuana - THC · Cannabidiol · Dystonia $\cdot$ Dyskinesias $\cdot$ Chorea $\cdot$ Tics

\section{Introduction}

Endocannabinoid receptors $\left(\mathrm{CB}_{1} \mathrm{R}\right.$ and $\left.\mathrm{CB}_{2} \mathrm{R}\right)$ are plentiful in the basal ganglia [1], implying they play a role in normal motor function and that pharmaceutical (or recreational) cannabis formulations, which are agonists at both sites, might alleviate symptoms of movement disorders. $\mathrm{CB}_{1} \mathrm{R}$ are expressed in $\gamma$-aminobutyric acid (GABA)ergic neurons of the caudate and striatum, presynaptic terminals in the globus pallidus externa and interna, substantia nigra pars reticulate and pars compacta, and are present in glutamatergic projections to and from the cortex and the subthalamic nucleus. In addition to GABAergic and glutamatergic pathways, dopaminergic inputs are also influenced by endocannabinoids. In general, the cannabinoid signals would be upregulated if a disease was marked by hypokinesis, such as in Parkinson disease (PD), as the cannabinoid ligands act overall to suppress movement, and would be decreased in hyperkinetic movement disorders such as Huntington disease (HD). However, paradoxical responses can occur during degeneration as the receptors in various parts of the basal ganglia die (Table 1).

The complexity of feedback loops in this region, with indirect actions of the endocannabinoid system modulating other inhibitory, excitatory or dopaminergic transmission, partially explains this. In addition, in degenerative diseases such as $\mathrm{HD}$ and $\mathrm{PD}$, progressive loss of specific structures, along with their endocannabinoid receptors occurs. The receptor loss will dampen any effects of $\mathrm{CB}_{1} / 2 \mathrm{R}$ agonists such as $\Delta^{9}$-tetrahydrocannabinol (THC) and cannabidiol (CBD). Other endocannabinoid receptors, such as transient receptor potential vannilloid-type 1 , may be successfully stimulated in early 
Table 1 Cannabis formulations used in various movement disorders

\begin{tabular}{|c|c|c|c|c|}
\hline Generic name & Trade name & Use & Dosage and component(s) & Reference \\
\hline \multicolumn{5}{|l|}{ PD } \\
\hline Cannabis extract & $\begin{array}{l}\text { Cannador } \\
\text { Not stated }\end{array}$ & $\begin{array}{l}\text { Dopa-induced dyskinesias/dystonia } \\
\text { Tremor/dystonia } \\
\text { dopa-induced dyskinesias }\end{array}$ & $\begin{array}{l}\Delta^{9}-\text { THC } 2.5+\text { CBD } 1.25 \\
100-600 \mathrm{mg} / \text { daily } \\
0.03 \mathrm{mg} / \mathrm{kg} / \text { daily } \\
25 \mathrm{mgTHC} / \mathrm{kg} / / \text { daily } \\
75 \mathrm{mg} / \text { daily }\end{array}$ & {$\left[7,10^{*} 16,17^{*}, 18^{*}\right]$} \\
\hline Rimonabant (CBD antagonist) & SR141716 & Dopa-induced dyskinesias & Experimental & [20] \\
\hline Inhaled botanical marijuana & - & Parkinson tremor and dyskinesias & $\begin{array}{l}1 \text { cigarette } 2.9 \% \text { THC } \\
\text { Survey of unsupervised } \\
\text { smoked marijuana } 0.5 \mathrm{gm} / \mathrm{cig}\end{array}$ & {$\left[13^{*}, 14,15,19\right]$} \\
\hline Nabilone & Cesamet & Levodopa-induced dyskinesias & $\begin{array}{l}\text { Synthetic cannabinoid } \\
0.03 \mathrm{mg} / \mathrm{kg} \\
0.03 \mathrm{mg} / \mathrm{kg}\end{array}$ & {$\left[10^{*}, 16\right]$} \\
\hline \multicolumn{5}{|l|}{ Dystonia } \\
\hline Dronabinol & Marinol & $\begin{array}{l}\text { Cervical dystonia } \\
\text { Dystonia and tics in MS }\end{array}$ & $\begin{array}{l}7.5 \mathrm{mg} \text { twice daily } \\
2.5 \mathrm{mg} \text { twice daily }\end{array}$ & {$\left[5^{*}, 11\right]$} \\
\hline $\mathrm{CBD}$ or cannabis extract & None & Primary dystonias & $\begin{array}{l}10 \mathrm{mg} / \mathrm{kg} / \text { day up to } 75 \mathrm{mg} / \text { day } \\
100 \mathrm{mg} \mathrm{CBD}\end{array}$ & {$\left[7,18^{*}, 23\right]$} \\
\hline Inhaled botanical marijuana & & $\begin{array}{l}\text { Spasms } \\
\text { Hemidystonia (in Wilson disease) }\end{array}$ & $\begin{array}{l}\text { Not stated } \\
1 \text { MJ Cigarette/dy } \\
3-4 \text { g/day }\end{array}$ & {$[6,8,9]$} \\
\hline \multicolumn{5}{|l|}{ HD } \\
\hline Nabilone & Cesamet & $\begin{array}{l}\text { Motor score no improvement, } \\
\text { some in chorea and NPI }\end{array}$ & $1-2 \mathrm{mg} /$ day & {$\left[23^{* \dagger}, 24^{*}\right]$} \\
\hline CBD or cannabis extract & None & & $10 \mathrm{mg} / \mathrm{kg} /$ day, mean $700 \mathrm{mg}$ & {$\left[21^{* \star}\right]$} \\
\hline \multicolumn{5}{|l|}{ Tourette syndrome } \\
\hline Botanical smoked marijuana & & & $\begin{array}{l}0.5-2.0 \text { cigarettes/day } \\
\text { One "cone"/night survey } \\
\text { (self-prescribed) }\end{array}$ & {$[25-27]$} \\
\hline THC capsule & None & Tics and vocalizations & $2.5 \mathrm{mg} \Delta^{9}-\mathrm{THC}$, maximum $10 \mathrm{mg} /$ day & {$\left[28^{\dagger}, 29+\right]$} \\
\hline
\end{tabular}

If no evidence classification is indicated, it means it was class IV. PD $=$ Parkinson disease; $\Delta^{9}$-THC $=\Delta^{9}$-tetrahydrocannabinol (the principal psychoactive agent); $\mathrm{CBD}=$ cannabidiol (a lesspsychoactive resin extract constituent of the plant Cannabis Sativa); MS = multiple sclerosis; HD = Huntington disease; NPI = Neuropsychiatric index

*Class I

${ }^{\dagger}$ Class II

\$Class III

stages of HD, but medications do not exist yet to test this. In fact, $\mathrm{CB}_{1} \mathrm{R}$ antagonists, similarly experimental at this stage, might be beneficial for hypokinetic symptoms such as hypokinesia in PD.

Contradictory and confusing efficacy has been reported when cannabis medications (or smoked phytocannabinoids) are used to treat movement disorder symptoms [2, 3]. Although the loss of receptors plays some role, more likely currently available cannabis preparations, which contain different amounts and combinations of cannabinoids (at least 60 have been described) with variable potency and psychoactive content (present in $\Delta^{9}$-THC but not CBD) with different, usually low, doses, make standardized comparisons impossible. Scoring methods, other than counting individual tics or choreiform movements, add to the researcher's difficulty in measuring efficacy. The potency, especially $\Delta^{9}$-THC content, is kept deliberately low to limit side effects (or patient recognition in those experienced with marijuana), which contributes to treatment failure. Studies are small with problematic recruitment for a substance that will require limitation of activities such as driving, use of a stigmatized medication, and of short duration (sometimes single dose) to avoid abuse or addiction [4]. Even obtaining study drug status in the USA requires working with the various government agencies, and is only becoming easier in the face of a serious epidemic of opiate overuse and toxicity. The Drug Enforcement Agency continues to classify medical cannabis as a Schedule I drug (that with no therapeutic use).

Investigation into cannabis' medicinal use began with promising case reports and anonymous surveys, followed by limited clinical research often conducted outside the USA, 
which has not proved sufficient to allow many evidence-based recommendations. Although overlap exists in individuals, in this review dyskinesias, dystonia, and chorea will be considered separately. Although tremor was studied in patients suffering from multiple sclerosis, there is no information on essential tremor. Tics will be considered separately, as the mechanism differs.

\section{Dystonia}

Dystonia involves overactivity of muscles required for normal movement, with extra force or activation of nearby but unnecessary muscles, including those that should be turned off to facilitate movement, and is often painful in addition to interfering with function. It can be primary, as in torticollis and blepharospasm/orofacial dyskinesias or dystonias (Meige syndrome) or as part of another condition such as HD and tardive dyskinesia after dopa-blocking drugs. The globus pallidus and substantia nigra pars reticularis contain $\mathrm{CB}_{1} \mathrm{R}$, with cannabinoids acting as neuromodulators and enhancing GABA release and reducing its reuptake [5].

In 1981, Marsden described improvement in a patient with torticollis who smoked cannabis [6]. An open-label series followed [7], and self-reported improvement with smoking marijuana was described in 2002 in a patient with central pain and dystonia and in a patient with Wilson disease [8, 9]. Cannabidiol showed improvement of 20-50\% by videotape review in 5 patients [9], but higher doses exacerbated tremor and hypokinesis in 2 patients with PD and levodopa-induced dystonia. Nabilone, a synthetic oral form of $\Delta^{9}-\mathrm{THC}$, which is available in the USA for other indications, was not found to be effective in 1 administration of escalating doses of $0.03 \mathrm{mg} / \mathrm{kg}$ using a dystonia rating scale; however, $3 / 15$ patients felt better for several days after its use [10]. Another currently available oral form of $\Delta^{9}$-THC, dronabinol, did not improve symptoms of cervical dystonia, as demonstrated by the Toronto Western Hospital Spasmodic Torticollis Rating Scale in a 3-week treatment trial [5]. Finally, response to dronabinol $2.5 \mathrm{mg}$ twice daily in a case report of dystonia (and tics) in a patient with multiple sclerosis who had previously reported symptom improvement after smoking marijuana [11].

Side effects described in these studies included hypotension and sedation at higher doses of nabilone [10], insomnia and tachycardia from dronabinol [5], and hypokinesia and tremor of PD [10].

\section{Dyskinesias from Levodopa (in Advanced PD)}

The plethora of endocannabinoid receptors in the basal ganglia, especially the globus pallidus interna, pars reticulata, and cerebellum indicate they must be playing a role in regulating tone and motor function through the effect of the endogenous cannabinoid ligand, arachidonylethanolamide (anadamide), on modulation of GABA transmission [12]. Many studies have been done with primate or rat models to determine if cannabinoid agonists or antagonists could act to suppress dyskinesias without exacerbating hypokinesis; however, translation to patients has proved difficult.

Since the initial observation in 1991 of no improvement of resting tremor in 5 patients who smoked one marijuana cigarette [13], surveys have been done asking patients with PD to say if they had tried marijuana on their own (presumably the smoked botanical form) and if so with what effect. Venderova sent surveys to 630 patients attending a movement disorders clinic in Prague, and of the 339 respondents, $25 \%$ had used marijuana. Of these 85 patients, 39 benefitted in rest tremor (31\%), bradykinesia (45\%), and dyskinesias (14\%), and continued its daily use [14]. A recent survey of Colorado residents with Parkinson using all types of complementary therapies found 9 using medical marijuana (4\%), reporting improvement of mood and sleep, but only 2 with improvement of motor symptoms, not specifically dyskinesias [15].

A small but class III randomized double-blind study using nabilone (synthetic $\Delta^{9}$-THC) showed a significant reduction in Rush score on levodopa-induced dyskinesias in 7 patients, observed and measured with the Rush dyskinesia scale [16], and 2 reported improvement in dystonia occurring in the off period for dopa. In a study of 17 patients using the oral preparation Cannador (2.5 mg $\Delta^{9}-\mathrm{THC} / 1.25 \mathrm{mg}$ CBD) no improvement was noted in dyskinesias as measured in Q32-34 of the Unified Parkinson's disease rating scale scale (the primary outcome), or other scales including Parkinson Disease Questionnaire-39 scale, nor was there a dose response [17]. The study by Carrol et al. [17] was the only one considered class I for the purposes of evidence-based recommendations. Various doses of cannabidiol were given to 21 patients over 6 weeks; no change was found in the total motor score, despite improvement in the quality of life section of the Unified Parkinson's disease rating scale if the target dose of $300 \mathrm{mg}$ daily was reached, which was possible in only $35 \%$ of the patients [18]. Finally, an open-"label" study of smoked marijuana in 22 Israeli patients showed improvement in the number of dyskinesias observed after dopa challenge, $30 \mathrm{~min}$ after smoking the cigarette [19]. In an interesting twist, a single dose of the $\mathrm{CB}_{1} \mathrm{R}$ antagonist rimonabant (SR141716) was found to have no effect on motor symptoms, or induced dyskinesias in 8 patients [20].

Side effects mentioned in the studies included hypotension, vertigo, hyperacusis, and disorientation and visual hallucinations [15], somnolence, dizziness and bad taste, with hypoglycemia in 1 patient [19], and, rarely, bradykinesia, but in the few studies where it was measured [17], there was no effect on cognitive function as measured by Mini Mental State Examination; in fact, an improvement in Mini Mental State 
Examination was noted, which was attributed to a practice effect but may have been precognitive (the 4 -week trial was too short to call cannabis neuroprotective).

In summary in PD, the symptom that responded best to cannabis, levodopa-induced dyskinesias, is a fairly rare complication of dopamine replacement in advanced cases. The role of cannabis in other symptoms of PD is unclear, and these symptoms vary according to the stage of neurodegeneration and also to the state of treatment with dopamine transmitter replacement. As there is the potential of cannabis worsening some symptoms, especially hypokinesia, very careful research must be done with PD.

\section{Dyskinesias in HD}

Abnormalities of motor function, along with psychiatric and cognitive dysfunction, are a main feature of $\mathrm{HD}$, a dominantly inherited neurodegenerative disease. Cannabis products have been most often used to ameliorate agitation and other psychiatric symptoms, but the presence of endocannibinoid receptors in the striatum, where they modulate GABA transmission and affect glutamate release, suggests a role for management of the excessive involuntary movements (choreoathetosis or dystonia) of HD. As in other degenerative processes, these receptors can decrease as the disease progresses, leaving less response to cannabinoid agonists as the brain's substrate changes. Obviously, current or prior use of dopamineblocking medication (neuroleptics), which can superimpose tardive dyskinesias on the direct movements of HD, will also change the therapeutic effects of cannabis.

Consroe et al. [21] first reported the clinical use of CBD in HD in 1991. This class III study of 15 patients receiving cannabis extract in capsule form $(10 \mathrm{mg} / \mathrm{kg})$, crossing to placebo over a 15 -week period, off neuroleptics for at least 2 weeks, found no difference in the chorea severity score of Marsden and Quinn, or on videotape and live assessment of chorea severity, nor on secondary end points of Shoulson and Fahn disability scores, finger tapping, or manipulation. Side effects, as checked off a symptom inventory, did not vary between placebo and treated patients. After a case report in a patient who had improved mood and movements after smoking marijuana and then taking prescribed nabilone, $1 \mathrm{mg}$ daily [22], the authors gave 1 or $2 \mathrm{mg}$ of nabilone to 37 patients in a class II study [23]. Despite improvement in the secondary measures of neuropsychiatric index and chorea score, the primary outcome, total motor score of the Unified Huntingdon Disease Rating Scale, showed only a modest response, with no dose response (i.e., $2 \mathrm{mg}$ was not better than $1 \mathrm{mg}$ ).

Drowsiness and forgetfulness were the main reported adverse events in both groups, with no increase in psychosis or euphoria in the treated group. In 1 case nabilone actually caused increased chorea [24].

\section{Tourette Syndrome Tics}

As in any condition influenced by anxiety, a nonspecific beneficial effect of cannabis might be expected, but given the presence of endocannibinoid receptors in the striatum, it is possible that a direct effect of cannabis is reducing the number of tics.

Success in treating symptoms of Tourette sydrome, including involuntary movements (tics) and compulsive behaviors, was first mentioned in an observation of 3 patients who, in 1988, noted improvement in tics and urges while smoking marijuana cigarettes [25], followed by another case of a patient remaining symptom free for a year while smoking marijuana daily [26]. In 1998 a survey of a larger population confirmed a reduction in tic or complete remission in $82 \%$ of patients [27]. The same authors used $\Delta^{9}$-THC capsules of varying strengths in a single dose in 12 patients (class II study) and reported improvement in scores of the Tourette Syndrome Symptom List and obsessive-compulsive behavior scores, with a decreased number of complex motor tics observed by the examiner [28]. The following year, in a study of 24 patients using the maximumstrength $\Delta^{9}$-THC capsule from the pilot study $(10 \mathrm{mg})$ for 6 weeks, a significant response in self-rated Tourette score and observer-rated scores, including the Tourette Syndrome Clinical Global Impression Scale, the Shapiro Tourette Syndrome Severity Scale, and the Yal Global Tic Severity Scale, as well as the review of video, was noted [29]. These were then summarized in a Cochrane review [30]. Little additional work was summarized in a more recent review [31]. Of note, improvements occurred without exacerbating performance on neuropsychologic testing [32].

Side effects were minimized by a simple technique of providing dronabinol after breakfast in order to slow its absorption and provide a steady level acting in the brain [29].

\section{Conclusions}

Although clinical studies in this area are difficult to do, even in countries where the use of cannabis has been allowed for years, there is a clear role for cannabis products in symptom management for these difficult conditions. The movement disorders are well-known to be worsened in patients who are anxious, but the careful observations reviewed above lead to the conclusion that there is a direct effect of cannabis in various formulations in some conditions, especially hyperkinetic symptoms. Caution in using a potential central nervous system depressant is always required in patients whose neurologic function is already compromised by disease, but 
larger studies will prove there is a promising role for this class of drug in the therapy of dyskinesias, tics, and possibly dystonia.

Required Author Forms Disclosure forms provided by the authors are available with the online version of this article.

\section{References}

1. Benarroch E. Endocannabinoids in basal ganglia circuits: implications for Parkinson disease. Neurology 2007;69:306-309.

2. Kluger B, Triolo P, Jones W, Jankovic J. The therapeutic potential of cannabinoids for movement disorders. Mov Disord 2015;30: 313-327.

3. Fernandez-Ruiz J. Endocannabinoids and motor disorders. Br J Pharmacol 2009;156:1029-1040

4. Koppel BS, Fife T, Brust JC, et al. Systematic review: efficacy and safety of medical marijuana in selected neurologic disorders: report of the Guideline Development Subcommittee of the American Academy of Neurology. Neurology 2014;82:1556-1563.

5. Zadikoff C, Wadia PM, Miyasaki J, et al. Cannabinoid, CB1 agonists in cervical dystonia: failure in a phase IIa randomized controlled trial. Basal Ganglia 2011;1:91-95.

6. Marsden CD. Treatment of torsion dystonia. In: Barbeau A (ed.) Disorders of movement, current status of modern therapy, Vol. 8. Lippincott, Philadelphia, PA, 1981, pp 81-104.

7. Consroe P, Sandyk R, Snider SR. Open label evaluation of cannabidiol in dystonic movement disorders. Intern J Neurosci 1986;30:277-282.

8. Chatterjee A, Almahrezi A, Ware M, Fitzcharles MA. A dramatic response to inhaled cannabis in a woman with central thalamic pain and dystonia. J Pain Symptom Manage 2002;24:4-6.

9. Uribe Roca MC, Micheli F, Viotti R. Cannabis sativa and dystonia secondary to Wilson's disease. Mov Disord 2005;20:113-115.

10. Fox SH, Kellett M, Moore AP, et al. Randomised, double-blind, placebo-controlled trial to assess the potential of cannabinoid receptor stimulation in the treatment of dystonia. Mov Disord 2002;17: 145-149.

11. Deutsch SI, Rosse RB, Connor JM, et al. Current status of cannabis treatment of multiple sclerosis with an illustrative case presentation of a patient with MS, complex vocal tics, paroxysmal dystonia, and marijuana dependence treated with dronabinol. CNS Spectr 2008;13:393-403.

12. Benbadis SR, Sanchez-Ramos J, Bozorg A, et al. Medical marijuana in neurology. Expert Rev Neurother 2014;14:1453-1465.

13. Frankel JP, Hughes A, Lees AJ, Stern GM. Marijuana for parkinsonian tremor. J Neurol Neurosurg Psych 1990;53:436-442.

14. Venderová K, Ružička E, Vořišsek V, Višnovský P. Survey on cannabis use in Parkinson's disease: subjective improvement of motor symptoms. Mov Disord 2004;19:1102-1106.

15. Finseth TA, Hedeman JL, Brown RP, II, et al. Self-reported efficacy of cannabis and other complementary medicine modalities by
Parkinson's disease patients in Colorado. Evid Based Complement Alternat Med 2015;2015:874849.

16. Sieradzan KA, Fox SH, Hill M, et al. Cannabinoids reduce levodopa-induced dyskinesia in Parkinson's disease: a pilot study. Neurology 2001;57:2108-2111.

17. Carroll CB, Bain PG, Teare L, et al. Cannabis for dyskinesia in Parkinson disease: a randomized double-blind crossover study. Neurology 2004;63:1245-1250.

18. Chagas MH, Zuardi AW, Tumas V, et al. Effects of cannabidiol in the treatment of patients with Parkinson's disease: an exploratory double-blind trial. J Psychopharmacol 2014;28:1088-1098.

19. Lotan I, Treves TA, Roditi Y, Djaldetti R. Cannabis (medical marijuana) treatment for motor and non-motor symptoms of Parkinson disease: an open-label observational study. Clin Neuropharmacol 2014;37:41-44.

20. Mesnage V, Houeto JL, Bonnet AM, et al. Neurokinin B, neurotensin, and cannabinoid receptor antagonists and Parkinson disease. Clin Neuropharmacol 2004;27:108-110.

21. Consroe P, Laguna J, Allender J, et al. Controlled clinical trial of cannabidiol in Huntington's disease. Pharmacol Biochem Behav 1991;40:701-708

22. Curtis A, Rickards H. Nabilone could treat chorea and irritability in Huntington's disease. J Neuropsych Clin Neurosci 2006;18:553554.

23. Curtis A, Mitchell I, Patel S, et al. A pilot study using nabilone for symptomatic treatment in Huntington's disease. Mov Disord 2009;24:2254-2259.

24. Müller-Vahl KR, Schneider U, Emrich HM. Nabilone increases choreatic movements in Huntington's disease. Mov Disord 1999; 14:1038-1040.

25. Sandyk R, Awerbuch G. Marijuana and Tourette's syndrome. J Clin Psychopharmacol 1988;8:444-445.

26. Hemming M, Yellowlees PM. Effective treatment of Tourette's syndrome with marijuana. J Psychopharmacol 1993;7:389-391.

27. Müller-Vahl KR, Kolbe H, Schneider U, Emrich HM. Cannabinoids: possible role in patho-physiology and therapy of Gilles de la Tourette syndrome. Acta Psychiatr Scand 1998;98: 502-506.

28. Müller-Vahl KR, Schneider U, Koblenz A, et al. Treatment of Tourette's syndrome with $\Delta 9$-Tetrahydrocannabinol (THC): a randomized crossover trial. Pharmacopsychiatry 2002;35:57-61.

29. Müller-Vahl KR, Schneider U, Prevedel H, et al. Delta 9tetrahydrocannabinol (THC) is effective in the treatment of tics in Tourette syndrome: a 6-week randomized trial. J Clin Psychiatry 2003;64:459-465

30. Curtis A, Clarke CE, Rickards HE. Cannabinoids for Tourette's syndrome (review). Cochrane Database Syst Rev 2009;(4): CD006565.

31. Müller-Vahl KR. Treatment of Tourette syndrome with cannabinoids. Behav Neurol 2013;27:119-124.

32. Müller-Vahl KR, Prevedel H, Theloe K, et al. Treatment of Toruette syndrome with Delta-9-Tetrahydrocannabinol $(\Delta 9$ THC): no influence on neuropsychological performance. Neuropsychopharmacology 2003;28:384-388. 